\title{
Long-term follow-up of acute type B aortic dissection: Ulcer-like projections in thrombosed false lumen play a role in late aortic events
}

\author{
Shunsuke Miyahara, MD, Nobuhiko Mukohara, MD, Masaomi Fukuzumi, MD, Naoto Morimoto, MD, \\ Hirohisa Murakami, MD, Keitaro Nakagiri, MD, and Masato Yoshida, MD
}

\begin{abstract}
Objective: Patients with Stanford type B dissection treated medically during the acute phase have a risk of surgery and aortic rupture during the chronic phase. We investigated the predictors for late aortic events by focusing on the false lumen status with computed tomography.
\end{abstract}

Methods: A total of 160 patients were enrolled in the study, with a mean follow-up interval of $44.6 \pm 25.4$ months. Patients were divided into 3 groups according to the false lumen status at the time of onset: group $\mathrm{T}$, thrombosed in 49 patients $(30.6 \%)$; group $\mathrm{U}$, thrombosed with ulcer-like projections in 52 patients $(32.5 \%)$; and group $\mathrm{P}$, patent in 59 patients $(36.9 \%)$.

\begin{abstract}
Results: The mean aortic enlargement rate of groups $\mathrm{U}$ and $\mathrm{P}$ was greater than that of group $\mathrm{T}(0.40 \pm 0.91 \mathrm{~mm} /$ month in group $\mathrm{U}, 0.44 \pm 0.49 \mathrm{~mm} / \mathrm{month}$ in group $\mathrm{P}$, and $-0.016 \pm 0.23 \mathrm{~mm} / \mathrm{month}$ in group T). The event-free rate in groups $\mathrm{U}$ and $\mathrm{P}$ was lower than in group T: 5-year event-free rates of $67.4 \% \pm 8.2 \%$ in group $\mathrm{U}$ and $57.7 \% \pm 10.9 \%$ in group $\mathrm{P}$ versus $95.0 \% \pm 4.9 \%$ in group T (group T vs group $\mathrm{U}: P=.0011$, group $\mathrm{U}$ vs group $\mathrm{P}: P=.96$, group $\mathrm{P}$ vs group T: $P=.0004)$. Cox regression analysis revealed that the false lumen status (patent or ulcer-like projections) $(P=.029)$, maximum aortic diameter at onset $(P<.0001)$, and patient age $(P=.0069)$ were predictors of the late aortic events.
\end{abstract}

Conclusions: In type B aortic dissection, a thrombosed false lumen with ulcer-like projections and a patent false lumen had an influence on late aortic dilation and late aortic events. (J Thorac Cardiovasc Surg 2011;142:e25-31)

Conservative medical management is usually the first choice of treatment for Stanford type B acute aortic dissection (AAD) without complications, such as rupture, malperfusion, and persistent pain. However, during the follow-up period some patients die of aortic rupture or show aortic dilation requiring intervention. At the time of onset, it is difficult to identify which patients will have these events in the chronic phase. In terms of late events, patients with type B $\mathrm{AAD}$ and a patent false lumen had poorer outcomes than those with a thrombosed false lumen (intramural hematoma [IMH]). There are 2 types of IMH: with or without ulcerlike projection (ULP). The role of ULPs as a prognostic factor in $\mathrm{AAD}$ has been discussed in the literature, ${ }^{1-3}$ although there are several conclusions and few descriptions with regard to the prognosis of ULPs. There is also controversy over the appropriate management for this condition. We compared the clinical features and prognosis of type B AAD among 3 groups divided according to false lumen status (patent, thrombosed, or ULPs in thrombosed false

\footnotetext{
From the Division of Cardiovascular Surgery, Hyogo Brain and Heart Center at Himeji, Hyogo, Japan.

Disclosures: Authors have nothing to disclose with regard to commercial support.

Received for publication Jan 8, 2010; revisions received Aug 11, 2010; accepted for publication Feb 9, 2011; available ahead of print March 25, 2011.

Address for reprints: Shunsuke Miyahara, MD, Hyogo Brain and Heart Center at

Himeji, Cardiovascular Surgery, 520 Saisho-Ko, Himeji, 670, Japan (E-mail:

shunnsuke0530@hotmail.com).

$0022-5223 / \$ 36.00$

Copyright (c) 2011 by The American Association for Thoracic Surgery

doi:10.1016/j.jtcvs.2011.02.015
}

lumen) and identified predictors of late aortic events on the basis of patients' parameters at the time of onset. We hypothesized that the prediction of risk factors from morphologic features and close follow-up with surgical interventions might improve the long-term outcome of uncomplicated type B AAD.

\section{MATERIALS AND METHODS \\ Study Population}

Between September 2000 and May 2009, we examined data from all 191 consecutive patients with type B AAD who visited the emergency department of the Hyogo Brain and Heart Center at Himeji at the time of onset. Type B AAD was defined as any nontraumatic dissection not involving the ascending aorta and presenting within 14 days of symptom onset. Of the 191 patients, 169 were followed up as cases treated successfully with antihypertensive therapy during the acute phase. The reasons for the exceptions during the acute phase included 4 cases of aortic rupture and 18 cases of emergency surgical interventions ( 2 cases of aortic rupture, 6 cases of persistent pain or enlargement of aortic diameter, and 10 cases of ischemia of limbs or abdominal organ). During the followup period, 5 patients were excluded because of surgery for other true aneurysms of the aorta. In those 5 patients, true aneurysms were diagnosed at the onset of AAD and were located separately proximal to the dissected aorta. Another 4 patients whose follow-up intervals were less than 6 months were excluded from this study. A total of 160 patients with type $\mathrm{B}$ AAD were enrolled in this study as outpatients. The mean follow-up time was 44.6 months (range, 6.3-99.9 months). The mean age of the patients at onset was 66.1 years (range, 18-89 years), and 37 patients $(23.1 \%)$ were female (Table 1$)$. We obtained informed consent from all patients. The study protocol was reviewed and approved by the institutional database and office records, and the study complied with the Declaration of Helsinki. 


$$
\begin{aligned}
& \text { Abbreviations and Acronyms } \\
& \begin{array}{ll}
\text { AAD } & =\text { acute aortic dissection } \\
\text { CT } & =\text { computed tomography } \\
\text { IMH } & =\text { intramural hematoma } \\
\text { PAU } & =\text { penetrating atherosclerotic ulcer } \\
\text { TEVAR } & =\text { thoracic endovascular aortic repair } \\
\text { ULP } & =\text { ulcer-like projection }
\end{array}
\end{aligned}
$$

\section{Diagnosis and Predictive Variables}

The diagnosis of type B dissection was confirmed with the use of enhanced computed tomography (CT) immediately after the emergency admission. Data were reviewed by an experienced radiologist in a blind manner. By using the results from this radiologic examination at emergency admission, we obtained data regarding the status in the false lumen (patent, thrombosed, or thrombosed false lumen complicated by ULPs) and the maximum diameter of the dissected aorta. In each patient, we measured the maximum aortic diameter in 2 segments: segment 1 , from an aortic bifurcation of the left subclavian artery to the descending aorta that is equal to the level of the tracheal bifurcation; and segment 2, below segment 1 . The maximum aortic diameter is defined as the largest short-axis diameter of the outer contour of aorta in the axial direction. This was measured at least twice, in the initial CT images performed at the time of onset and in the most recent follow-up CT images. In patients who underwent surgery during the chronic phase, the diameter was measured on CT images obtained immediately before surgery. The mean aortic enlargement rate (diameter) was obtained by dividing the difference in the maximum aortic diameter between the initial and the most recent $\mathrm{CT}$ images (millimeters) by the interval (months) in the same segment. CT examinations were performed with a variety of scanners. CT examinations were performed with a 16-slice helical CT scanner (Aquilion 16; Toshiba Medical Systems Co, Ltd, Tokyo, Japan) from September 2000 to September 2004, and with a 64-slice helical CT scanner (Aquilion 64, Toshiba Medical Systems Co, Ltd) from October 2004 to , all obtaining axial images with contiguous 7.0-mm-thick sections from the top of the aortic arch to the iliac bifurcation. Contrast-enhanced CT was performed with a bolus injection of $100 \mathrm{~mL}$ iopamidol (Iopamiron 300 ; Schering, Tokyo, Japan) at a rate of $3.5 \mathrm{~mL} / \mathrm{sec}$ via an automated injector. All CT images were available on the picture archiving and communications system. These data on the acute phase and the basic characteristics (age, sex, concomitant hypertension, ischemic heart disease, and peripheral artery diseases, including cerebrovascular and the extremities) are shown in Table 1 as predictive variables for aortic enlargement during the chronic phase. All 160 patients were divided into 3 groups according to clinical features associated with the status of the false lumen. We defined a thrombosed false lumen as a false lumen that was not enhanced at the early or delayed phase. Forty-nine patients $(30.6 \%)$ had a thrombosed false lumen, labeled as group T. ULPs were defined as any focal, blood-filled pouch projecting into the thrombosed false lumen. Fifty-two patients (32.5\%) fulfilled this definition, labeled as group U. A patent false lumen is a false lumen that was enhanced at an early or delayed phase. There were 59 patients $(36.9 \%)$ who met this status of the false lumen, labeled as group P. Nineteen patients $(32.2 \%)$ in group P had partial thrombosis of the false lumen in which both flow and thrombus were present. Group P also included 4 patients with connective tissue disorders.

We investigated the predictors for late aortic events defined as an end point of progressive aortic pathology including rupture and expansion or malperfusion with need for open surgery or thoracic endovascular aortic repair (TEVAR).

\section{Treatment and Follow-up}

Almost all patients with type B AAD received calcium-channel blockers by continuous intravenous infusion to control blood pressure immediately after admission to the Hyogo Brain and Heart Center at Himeji. Some patients required additional nitric acid agents. When oral administration was possible, oral formulations of these agents were administered. In principle, patients without severe heart failure or obstructive pulmonary disease received $\beta$-blockers concurrently with additional calcium-channel blockers and angiotensinII receptor blocker as appropriate. While maintaining adequate urine production, blood pressure was controlled with a target systolic level of $120 \mathrm{~mm} \mathrm{Hg}$. After discharge, patients continued to receive oral medications at a local clinic or our hospital. In addition, surgery was performed in patients with complications such as rupture or an increased aortic diameter. Follow-up was obtained by office visits and telephone interviews with the patients or their families.

\section{Statistical Analysis}

\begin{tabular}{|c|c|c|c|c|}
\hline Characteristics & $\begin{array}{c}\text { Group } T \\
\mathbf{N}=49 \\
(30.6 \%)\end{array}$ & $\begin{array}{c}\text { Group U } \\
\mathbf{N}=\mathbf{5 2} \\
(\mathbf{3 2 . 5} \%)\end{array}$ & $\begin{array}{c}\text { Group P } \\
\mathbf{N}=\mathbf{5 9} \\
(\mathbf{3 6 . 9} \%)\end{array}$ & $P$ value \\
\hline Age, $y($ mean $\pm S D$, range $)$ & $69.5 \pm 8.9,54-89$ & $70.5 \pm 7.9,53-85$ & $60.0 \pm 15.4,18-87$ & $*$ \\
\hline Sex (female, \%) & 36.7 & 17.3 & 16.9 & $\dagger$ \\
\hline Peripheral artery disease $(\%)$ & 4.1 & 13.4 & 8.5 & NS \\
\hline Hypertension $(\%)$ & 34.7 & 38.4 & 30.5 & NS \\
\hline Ischemic heart disease $(\%)$ & 6.1 & 5.8 & 5.1 & NS \\
\hline \multicolumn{5}{|l|}{ CT findings at onset } \\
\hline Aortic dilation in segment $1, \mathrm{~N}(\%)$ & $44(89.8)$ & $35(67.4)$ & $47(79.7)$ & $\ddagger$ \\
\hline Extent of dissection, $\mathrm{N}(\%)$ & & & & $\S$ \\
\hline DeBakey IIIa & $21(42.9)$ & $25(48.1)$ & $3(5.1)$ & \\
\hline DeBakey IIIb & $28(57.1)$ & $27(51.9)$ & $56(94.9)$ & \\
\hline Maximum aortic diameter at onset (mm) & $36.5 \pm 5.1$ & $41.5 \pm 6.0$ & $39.0 \pm 6.3$ & $\|$ \\
\hline
\end{tabular}

All continuous variables are expressed as the mean \pm standard deviation. Comparison of the clinical and radiologic characteristics was performed by the chi-square analysis for categoric variables and by Student $t$ test for continuous variables. Cox regression analysis was used to identify the predominant predictors for late aortic events throughout the entire

TABLE 1. Basic characteristics among groups

$S D$, Standard deviation; $C T$, computed tomography; $N S$, not significant. *Group T vs group U: NS, group U vs group P: $P<.0001$, group $\mathrm{P}$ vs group T: $P=.0002$. $\dagger$ Group T vs group $\mathrm{U}: P=.028$, group $\mathrm{U}$ vs group $\mathrm{P}$ : NS, group $\mathrm{P}$ vs group T: $P=.020$. NS, group U vs group $\mathrm{P}: P<.0001$, group $\mathrm{P}$ vs group T: $P<.0001$. $\|$ Group T vs group $\mathrm{U}: P<.0001$, group U vs group $\mathrm{P}: P=.037$, group $\mathrm{P}$ vs group T: $P=.028$. 
follow-up period. The values of actuarial freedom from late aortic events and survival were computed by using the Kaplan-Meier technique and compared using the log-rank test. These data analyses were performed with StatView 5.0 for Windows (SAS Institute Inc, Cary, NC). Receiver operating characteristic curve was processed by SPSS 13.0 for Windows (SPSS, Inc, Chicago, Ill).

\section{RESULTS}

Differences in basic characteristics among the 3 groups are shown in Table 1 . There were more female patients in group $\mathrm{T}$ compared with the other groups (group $\mathrm{T}$ vs group $\mathrm{U}: P=.028$, group $\mathrm{U}$ vs group $\mathrm{P}: P=.96$, group $\mathrm{P}$ vs group T: $P=.020$ ). A significant difference was not seen among groups in terms of hypertension, concomitant ischemic heart disease, and peripheral artery disease. Patients in group $\mathrm{P}$ were significantly younger than patients in the other 2 groups, with a mean age of $60.0 \pm 15.4$ years, versus $69.5 \pm 8.9$ years in group $T$ and $70.5 \pm 7.9$ years in group $\mathrm{U}$ (group T vs group $\mathrm{U}: P=.54$, group $\mathrm{U}$ vs group $\mathrm{P}$ : $P<.0001$, group $\mathrm{P}$ vs group T: $P=.0002$ ). The maximum aortic diameters at the onset were the largest in group $\mathrm{U}$, with a mean diameter of $41.5 \pm 6.0 \mathrm{~mm}$, versus $39.0 \pm$ $6.3 \mathrm{~mm}$ in group $\mathrm{P}$ and $36.5 \pm 5.1 \mathrm{~mm}$ in group $\mathrm{T}$ (group T vs group $\mathrm{U}: P<.0001$, group $\mathrm{U}$ vs group $\mathrm{P}: P=.037$, group $\mathrm{P}$ vs group T: $P=.028$ ). The largest segment of the aorta in each group is shown in Table 1. Patients in group $\mathrm{T}$ tended to have proximal aortic dilatation in the descending aorta (segment 1). Patients who had the largest aortic diameter in segment 2 showed enlargement in the descending or thoracoabdominal aorta, not in the lower abdominal aorta. During the follow-up period, some patients have had a shift to other false lumen status. The number of patients who crossed over into other groups is shown in Figure 1. The mean aortic enlargement rate (diameter) is shown in Table 2. Patients whose maximum aortic diameter decreased were mostly in group T. Almost all patients in group $\mathrm{P}$ showed aortic dilation during a follow-up period. In group $\mathrm{U}$, some patients showed a reduction in the maximum aortic diameter, whereas others showed a rapid enlargement of the maximum aortic diameter in a short

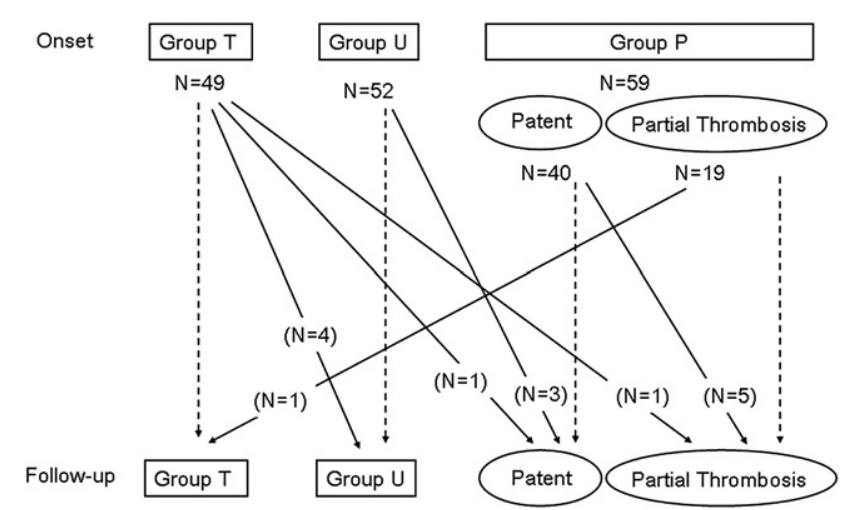

FIGURE 1. The number of cross-overs between groups. period. The mean aortic enlargement rate in groups $U$ and $\mathrm{P}$ was greater than that in group $\mathrm{T}$, with statistical significance $(0.40 \pm 0.91 \mathrm{~mm} /$ month in group $\mathrm{U}, 0.44 \pm 0.49$ $\mathrm{mm} / \mathrm{month}$ in group $\mathrm{P}$, and $-0.016 \pm 0.23 \mathrm{~mm} / \mathrm{month}$ in group T) (group T vs group $\mathrm{U}: P=.0024$, group $\mathrm{U}$ vs group $\mathrm{P}: P=.78$, group $\mathrm{P}$ vs group T: $P<.0001)$.

During the follow-up period, 26 patients $(16.3 \%)$ underwent elective surgery because of aortic diameter enlargement. Five patients $(3.1 \%)$ had aortic rupture; however, only 1 patient survived with surgery. One patient with a 55-mm thoracic aneurysm refused operation because of her pulmonary comorbidities. The operative procedures performed in these 27 patients and other aortic events are shown in Table 3. Figure 2, $A$ shows the Kaplan-Meier curve indicating freedom from aortic events. The mean follow-up for the 160 patients examined in this analysis was $33.5 \pm 20.5$ months (range, 2.0-88.0 months). The event-free rate at 1,3 , and 5 years was $92.2 \% \pm 2.2 \%$, $84.2 \% \pm 3.2 \%$, and $71.0 \% \pm 5.5 \%$, respectively. Figure 2, $B$ shows the Kaplan-Meier event-free curves stratified by the groups. The event-free rate was highest in group $\mathrm{T}$, with 1-, 3-, and 5-year event-free rates of $100.0 \% \pm$ $0.0 \%, 100.0 \% \pm 0.0 \%$, and $95.0 \% \pm 4.9 \%$, respectively, versus $90.3 \% \pm 4.1 \%, 76.0 \% \pm 6.4 \%$, and $67.4 \% \pm 8.2 \%$ in group $\mathrm{U}$ and $87.7 \% \pm 4.4 \%, 80.2 \% \pm 5.8 \%$, and $57.7 \%$ $\pm 10.9 \%$ in group $\mathrm{P}$, respectively. A separate log-rank test showed that the event-free rate in groups $\mathrm{U}$ and $\mathrm{P}$ was significantly lower than in group $\mathrm{T}$ (group $\mathrm{T}$ vs group $\mathrm{U}$ : $P=.0011$, group $\mathrm{U}$ vs group $\mathrm{P}: P=.96$, group $\mathrm{P}$ vs group T: $P=.0004)$. A subgroup analysis was performed, which excluded 4 patients with connective tissue disorders in group $\mathrm{P}$, that showed no difference in the event-free rate compared with the entire study group analysis ( $\mathrm{T}$ vs $\mathrm{U}$ : log-rank $P=.0007, \mathrm{U}$ vs $\mathrm{P}: \log$-rank $P=.8989, \mathrm{P}$ vs T: $\log$-rank $P=.0013$ ). The cumulative survival of the entire study group at 1,3 , and 5 years was $98.7 \% \pm 0.9 \%, 92.2 \%$ $\pm 2.4 \%$, and $87.2 \% \pm 3.4 \%$, respectively (Figure $2, C$ ), and there was no significant difference among the groups (mean follow-up: $44.6 \pm 25.4$ months; range, 6.3-99.9 months) (Figure $2, D$ ). Survival at 5 years in groups $\mathrm{T}$, $\mathrm{U}$, and $\mathrm{P}$ was $93.8 \% \pm 4.3 \%, 78.7 \% \pm 2.1 \%$, and $91.9 \% \pm$ $4.0 \%$, respectively (group $\mathrm{T}$ vs group $\mathrm{U}: P=.67$, group $\mathrm{U}$ vs group $\mathrm{P}: P=.12$, group $\mathrm{P}$ vs group T: $P=.44$ ).

Among the 160 patients during the chronic phase, 142 survived and 18 died, of whom 4 died of aortic rupture ( 2 in group $\mathrm{U}$ and 2 in group $\mathrm{P}$ ). The other 14 deaths were not caused by aortic events: subarachnoid hemorrhage in 3 patients, respiratory failure in 3 patients, malignancy in 2 patients, pneumonia in 2 patients, trauma in 1 patient, heart failure in 1 patient, renal failure in 1 patient, and sudden death in 1 patient in group $\mathrm{T}$. There was no hospital death among the patients who underwent surgical aortic replacement or endovascular repair in the chronic phase. The survival between the event group $(\mathrm{N}=32$; including death 
TABLE 2. Growth length of maximum aortic diameter

\begin{tabular}{|c|c|c|c|c|}
\hline & $\begin{array}{c}\text { Group } T \\
\mathbf{N}=\mathbf{4 9}\end{array}$ & $\begin{array}{c}\text { Group } \mathbf{U} \\
\mathbf{N}=\mathbf{5 2}\end{array}$ & $\begin{array}{c}\text { Group P } \\
\mathbf{N}=\mathbf{5 9}\end{array}$ & $P$ value \\
\hline Diameter $(\mathrm{mm} / \mathrm{mo})$ & $-0.016 \pm 0.23$ & $0.40 \pm 0.91$ & $0.44 \pm 0.49$ & $*$ \\
\hline Cases of growing, $\mathrm{N}(\%)$ & $19(38.8)$ & $42(80.7)$ & 57 (96.6) & $\dagger$ \\
\hline
\end{tabular}

*Group T vs group U: $P=.0024$, group $\mathrm{U}$ vs group $\mathrm{P}: P=.78$, group $\mathrm{P}$ vs group T: $P<.0001$. †Group T vs group $\mathrm{U}: P<.0001$, group $\mathrm{U}$ vs group $\mathrm{P}: P=.0073$, group $\mathrm{P}$ vs group T: $P<.0001$.

of aortic rupture) and non-event group $(\mathrm{N}=128)$ showed no significant difference (Figure 2,E).

The 10 variables listed in Table 4 correlated with aortic events throughout the entire follow-up period. With the use of univariate analysis, age $(61.3 \pm 16.6$ years in event group, vs $67.6 \pm 10.8$ years in non-event group, $P=.010)$, maximum aortic diameter at onset (43.9 \pm $7.34 \mathrm{~mm}$ in event group, vs $37.8 \pm 5.11 \mathrm{~mm}$ in non-event group, $P<.0001$ ), and false lumen status (patent or thrombosed with ULPs) (group P or U) $(P=.0002)$ were significantly correlated with late aortic events. To determine the statistical significance of the predictor variables, Cox regression analysis was performed and revealed that age $(P=.0069)$, maximum diameter at onset $(P<.0001)$, and false lumen status (patent or ULPs) $(P=.029)$ were significant predictive factors of late aortic events (Table 4). The maximum aortic diameter at onset showed greater statistical significance. Sensitivity and specificity of the maximum aortic diameter to the late aortic events were $61.3 \%$ and $73.4 \%$ with a maximum aortic diameter cutoff of $40.5 \mathrm{~mm}(P<.001 ; 95 \% \mathrm{CI}, 0.642-0.844)$.

\section{DISCUSSION}

Patients with acute type B aortic dissection without complications such as rupture or organ ischemia should be treated medically in the acute phase. ${ }^{4,5}$ In the chronic phase, some patients who survived through the acute phase die of aortic rupture. To prevent aortic rupture in the chronic phase, it is important to carefully observe all patients and make a decision about surgical interventions for patients with an enlarged aortic diameter. Many studies have indicated predictors of a late aortic event. ${ }^{6-11}$

TABLE 3. Details of the late aortic events

\begin{tabular}{ll}
\hline \multicolumn{1}{c}{ Late aortic events $\mathbf{N}(\%)$} & \\
\hline Elective surgery & $9(28.1)$ \\
Descending aortic replacement & $8(25.0)$ \\
Thoracoabdominal aortic replacement & $5(15.6)$ \\
Total arch replacement & $3(9.4)$ \\
TEVAR & $1(3.1)$ \\
Abdominal aortic replacement & \\
Emergency surgery & $1(3.1)$ \\
Descending aortic replacement & $4(12.5)$ \\
Rupture & $1(3.1)$ \\
Other & \\
\hline$T E V A R$, Thoracic endovascular aortic repair.
\end{tabular}

The present study shows that a late aortic event in type B AAD is correlated with 3 independent predictors: false lumen status (patent or thrombosed with ULPs), patient age, and maximum aortic diameter at onset. Previous studies have suggested a higher risk of late aortic events in patients with a patent false lumen than in those with a thrombosed false lumen. ${ }^{8-10,12}$ We demonstrated that patients with a thrombosed false lumen and ULPs have an equally poor prognosis as those with a patent false lumen, with a relatively large cohort and a long follow-up period.

In the present series, patients with a patent false lumen had a greater tendency to have an enlarged aortic diameter compared with those with a thrombosed false lumen. Expansion of aortic diameter during the chronic phase of type B AAD is primarily caused by enlargement of the patent false lumen, and patients with this sign have a significant tendency to undergo surgical interventions or die of aortic rupture. ${ }^{10,11,13}$ Williams and colleagues ${ }^{14}$ showed that increases in the size of the patent, elastin-poor, pressurized false lumen caused an enlargement of overall aortic diameter in an in vitro model. ${ }^{14}$

For several decades, it has been said that there is an atherosclerotic lesion with ulceration that penetrates the internal elastic lamina, often resulting in hematoma within the media of the aortic wall, and that has been recognized as an atypical aortic dissection. ${ }^{15}$ These penetrating atherosclerotic ulcers (PAUs) are mostly visualized radiologically as ULPs. Our study indicated that patients with a thrombosed false lumen and complicating ULPs were at risk for late aortic events, as well as those with a patent false lumen, and the mean aortic enlargement rate of this entity was closer to that of patients with a patent false lumen. It has been thought that ULPs frequently tended to enlarge and progress to aneurysms. ${ }^{2,16-18}$ Tisnado and associates ${ }^{19}$ reported that ULPs in an aortogram may progress into establishing a false lumen, and this indicates a possible rupture. Many ULPs progressed to saccular aneurysms or recanalized into a false lumen in this study (Figure 3, $A, B$ ). Ganaha and colleagues ${ }^{1}$ clarified the differences of clinical features and prognosis between IMH with PAU and IMH without PAU by showing their early outcome. Jang and colleagues ${ }^{2}$ demonstrated that the incidence of complications, such as aneurysm formations and dissections, in IMH with PAU was higher than in IMH without PAU. Our results virtually followed these 2 studies. On the other hand, Quint and colleagues ${ }^{3}$ showed that most ULPs remain unchanged over 

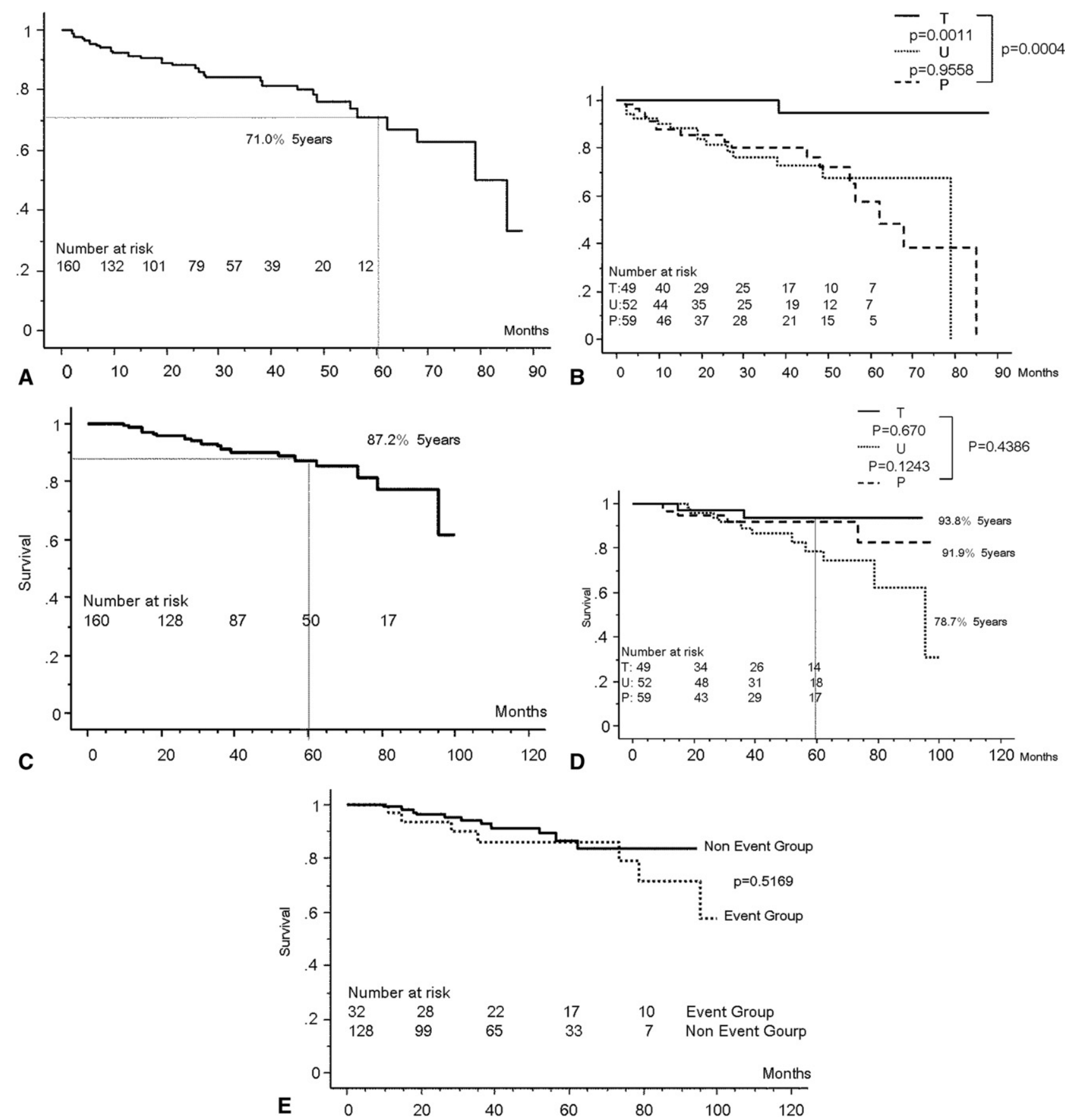

FIGURE 2. A, Freedom from aortic events in entire study group. B, Freedom from aortic events in each group; $P$ values were calculated by the log-rank test. C, Cumulative survival of entire study group. D, Cumulative survival of each group; $P$ values were calculated by the log-rank test. E, Cumulative survival of event group $(\mathrm{N}=32)$ and non-event group $(\mathrm{N}=128) ; P$ values were calculated by the log-rank test.

time and that one third of ULP lesions progress with mild aortic enlargement; the mean increase in aortic diameter was $15 \%$ (range, $5 \%-45 \%$ ) in follow-up CT performed 5 to 50 months (mean, 19.8 months) after discharge. The definition of ULP still remains unclear; it is considered to represent the site of an intimal tear, the site of occlusion, or the detachment of the orifice of aortic branches or
PAUs. ${ }^{2,20}$ In our cohort, we regarded any blood-filled pouch projecting into the thrombosed false lumen as a ULP, and patients with ULPs were more likely to have a poor prognosis because of late aortic events.

In total, 4 dissection-related deaths occurred throughout the entire study period, and all of them had an aortic rupture at other hospitals or were transferred to our hospital in 
TABLE 4. Statistical analysis of predictors for late aortic events

\begin{tabular}{lccc}
\hline \multicolumn{1}{c}{ Variables } & Univariate $\boldsymbol{P}$ & \multicolumn{2}{c}{ Cox proportional hazard analysis } \\
\cline { 2 - 4 } Age & .0103 & $\boldsymbol{P}$ value & Hazard ratio \\
Female & .5117 & .0069 & 0.965 \\
Aortic dilation in distal arch & .1221 & & \\
Max diameter at onset & $<.0001$ & & \\
Patent false lumen or ULPs & .0002 & $<.0001$ & 1.151 \\
Ischemic heart disease & .1468 & .029 & 9.578 \\
Peripheral artery diseases & .4013 & & \\
Hypertension & .2119 & & \\
DeBakey IIIa & .4402 & & \\
Connective tissue disorder & .1287 & & \\
\hline
\end{tabular}

$C I$, Confidence interval; $U L P$, ulcer-like projection.

shock. In balancing the risk of aortic rupture, it is important to closely observe patients in risk groups and assess whether they would be a candidate for surgical interventions. Estimating the substantial risk associated with surgery is also fundamental. Otherwise, the cumulative survival among our 3 groups showed no significant differences. This means that our surgical results were acceptable, and the surgical interventions achieved a successful outcome in a long followup period. On the other hand, only 3 patients were managed with endovascular repair in the late chronic phase ( 2 in group $\mathrm{P}$ and 1 in group $\mathrm{T}$, who crossed over to group $\mathrm{U}$ ). Nienaber and colleagues ${ }^{21}$ did not demonstrate a survival benefit of prophylactic TEVAR in the INSTEAD trial; how- ever, they showed evidence of aortic remodeling, expansion of the thoracic true lumen, and thrombosis of the false lumen 2 years after intervention. The morphologic feature of their study group was patent false lumen: completely patent in $63.9 \%$ and partial thrombosis in $36.1 \%$. Nienaber and colleagues applied prophylactic interventions in the early chronic phase. ${ }^{21}$ Although our approach for type B aortic dissection was different from that of INSTEAD, endovascular repair in the early chronic phase has benefit for a risk group, especially patients with pulmonary comorbidities or the elderly. A prophylactic TEVAR for a thrombosed false lumen with ULPs has substantial merit, as well as for a patent false lumen.
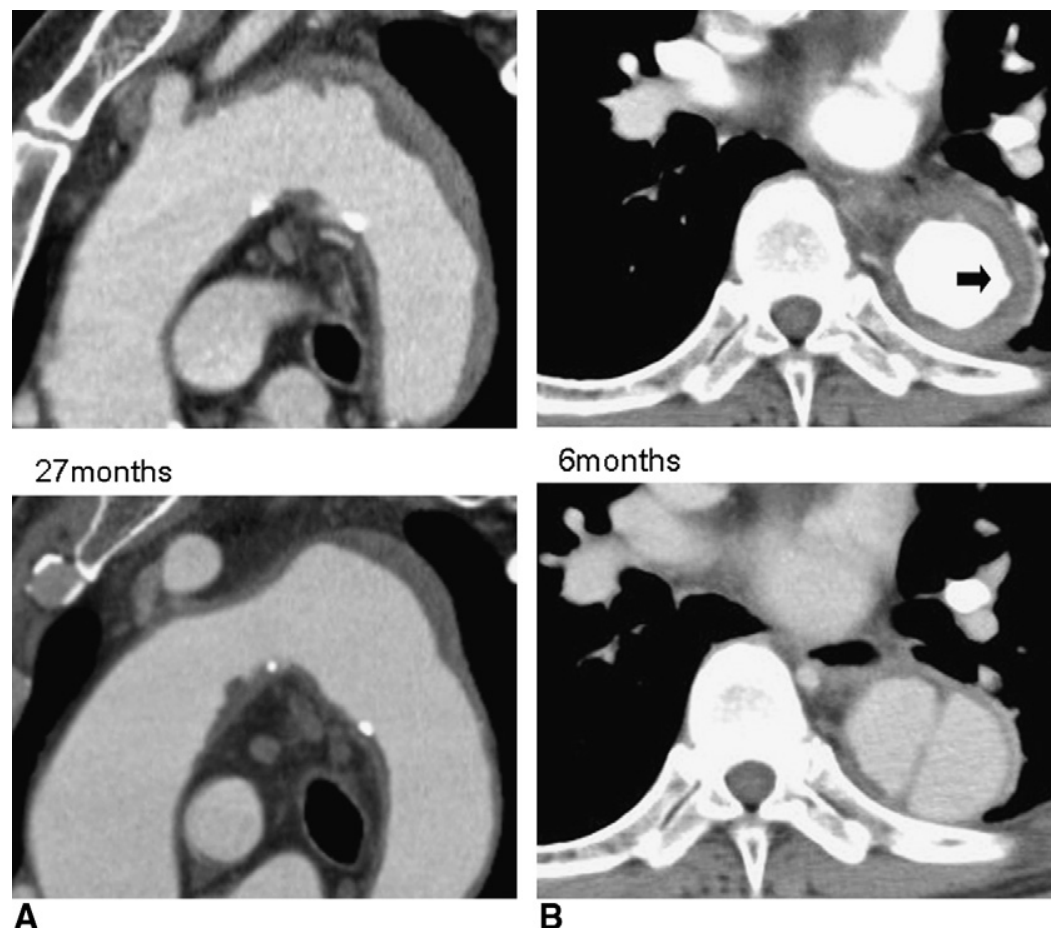

6 months

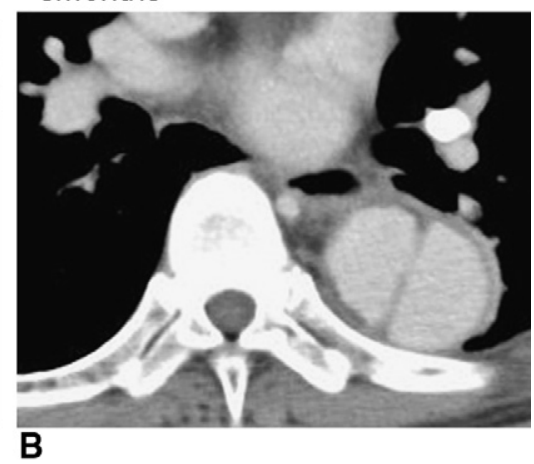

FIGURE 3. A, ULP in distal arch progressed to a saccular aneurysm 27 months later. B, ULP (black arrow) in descending aorta recanalized into false lumen 6 months later. 
Another finding of the present investigation is that aortic diameter at onset was a strong independent risk factor of late aortic events. Many previous studies reached an agreement about this result with a cutoff diameter of 40 to $45 \mathrm{~mm}^{6-8,11,12}$ We derived the cutoff diameter of $40.5 \mathrm{~mm}$ from a receiver operating characteristic curve. The maximum aortic diameter was largest in group $\mathrm{U}$, which was statistically significant.

\section{Study Limitations}

There was a relatively small number of patients with a follow-up period more than 5 years in each group. In addition, a variety of CT scanners were used according to the study period.

\section{CONCLUSIONS}

We evaluated the prognosis in patients with type B AAD who received medical treatment in their initial hospitalization. The incidence of late aortic events was higher in patients with a thrombosed false lumen complicated by ULPs and in patients with a patent false lumen. When patients have these 2 types of false lumen, especially with a maximum aortic diameter greater than $40 \mathrm{~mm}$ at onset, careful and regular follow-up CT examinations are required, and surgical interventions including TEVAR should be considered in case of aortic enlargement.

\section{References}

1. Ganaha F, Miller DC, Sugimoto K, Do YS, Minamiguchi H, Saito H, et al. Prognosis of aortic intramural hematoma with and without penetrating atherosclerotic ulcer: a clinical and radiological analysis. Circulation. 2002;106:342-8.

2. Jang YM, Seo JB, Lee YK, Chae EJ, Park SH, Kang JW, et al. Newly developed ulcer-like projection (ULP) in aortic intramural haematoma on follow-up CT: is it different from the ULP seen on the initial CT? Clin Radiol. 2008;63:201-6.

3. Quint LE, Williams DM, Francis IR, Monaghan HM, Sonnad SS, Patel S, et al. Ulcerlike lesions of the aorta: imaging features and natural history. Radiology. 2001;218:719-23.

4. Glower DD, Fann JI, Speier RH, Morrison L, White WD, Smith LR, et al. Comparison of medical and surgical therapy for uncomplicated descending aortic dissection. Circulation. 1990;82(Suppl IV):IV-39-46.
5. Jex RK, Schaff HV, Piehler JM, King RM, Orszulak TA, Danielson GK, et al. Early and late results following repair of dissection of the descending thoracic aorta. J Vasc Surg. 1986;3:226-37.

6. Akutsu K, Nejima J, Kiuchi K, Sasaki K, Ochi M, Tanaka K, et al. Effects of the patent false lumen on the long-term outcome of type B acute aortic dissection. Eur J Cardiothorac Surg. 2004;26:359-66.

7. Onitsuka S, Akashi H, Tayama K, Okazaki T, Ishihara K, Hiromatsu S, et al. Long-term outcome and prognostic predictors of medically treated acute type b aortic dissections. Ann Thorac Surg. 2004;78:1268-73.

8. Marui A, Mochizuki T, Mitsui N, Koyama T, Kimura F, Horibe M. Toward the best treatment for uncomplicated patients with type $\mathrm{b}$ acute aortic dissection: a consideration for sound surgical indication. Circulation. 1999;100(Suppl II):II-275-80.

9. Sueyoshi E, Sakamoto I, Hayashi K, Yamaguchi T, Imada T. Growth rate of type B aortic dissection. Circulation. 2004;110(Suppl II):II-256-61.

10. Blount KJ, Hagspiel KD. Aortic diameter, true lumen, and false lumen growth rates in chronic type B aortic dissection. AJR Am J Roentgenol. 2009;192: W222-9.

11. Hata M, Sezai A, Niino T, Yoda M, Wakui S, Unosawa S, et al. Prognosis for patients with type B acute aortic dissection. Circ J. 2007;71:1279-82.

12. Kunishige H, Myojin K, Ishibashi Y, Ishii K, Kawasaki M, Oka J. Predictors of surgical indications for acute type B aortic dissection based on enlargement of aortic diameter during the chronic phase. Jpn J Thorac Cardiovasc Surg. 2006; 54:477-82.

13. Kelly AM, Quint LE, Nan B, Zheng J, Cronin P, Deeb GM, et al. Aortic growth rates in chronic aortic dissection. Clin Radiol. 2007;62:866-75.

14. Williams DM, LePage MA, Lee DY. The dissected aorta. I. Early anatomic changes in an in vitro model. Radiology. 1997;203:23-31.

15. Stanson AW, Kazmier FJ, Hollier LH, Edwards WD, Pairolero PC, Sheedy PF et al. Penetrating atherosclerotic ulcers of the thoracic aorta: natural history and clinicopathologic correlations. Ann Vasc Surg. 1986;1:15-23.

16. Obitsu Y, Ishimaru S, Ichihashi H, Shimazaki T, Kawaguchi S, Ishikawa M. Clinical results of acute closing aortic dissection. Jpn J Thorac Cardiovasc Surg. 1998;46:689-94.

17. Sueyoshi E, Matsuoka Y, Sakamoto I, Uetani M, Hayashi K, Narimatsu M. Fate of intramural hematoma of the aorta: CT evaluation. J Comput Assist Tomogr. 1997;21:931-8.

18. Lee YK, Seo JB, Jang YM, Do KH, Kim SS, Lee JS, et al. Acute and chronic complications of aortic intramural hematoma on follow-up computed tomography: incidence and predictor analysis. J Comput Assist Tomogr. 2007;31:435-40.

19. Tisnado J, Cho SR, Beachley MC, Vines FS. Ulcerlike projections: a precursor angiographic sign to thoracic aortic dissection. Am J Roentgenol. 1980;135: 719-22.

20. Nienaber CA, von Kodolitsch Y, Petersen B, Loose R, Helmchen U, Haverich A et al. Intramural hemorrhage of the thoracic aorta diagnostic and therapeutic implications. Circulation. 1995;92:1465-72.

21. Nienaber CA, Rousseau H, Eggebrecht H, Kische S, Fattori R, Rehders TC, et al Randomized comparison of strategies for type $\mathrm{b}$ aortic dissection. The INvestigation of STEnt Grafts in Aortic Dissection (INSTEAD) Trial. Circulation. 2009; 120:2519-28. 